\title{
Operative treatment of cerebral arteriovenous aneurysm of vein of Galen complicated by congestive heart failure
}

\author{
KAJ LILLQUIST, JENS HAASE, AND PER THAYSSEN
}

From the Paediatric Department, Department of Neurosurgery, and Department of Clinical Physiology, Odense University Hospital, Denmark

SUMMARY A rare cause of congestive heart failure in the neonatal period is an intracranial arteriovenous malformation, but this condition should be borne in mind when there is unexplained right-sided congestive heart failure. A case is reported of an aneurysm of the great vein of Galen, complicated by congestive heart failure. Successful surgical treatment was carried out using a two-stage procedure.

Intracranial arteriovenous malformations are a rare cause of congestive heart failure during the neonatal period. Both conservative and active surgical treatment of these malformations involves considerable risk (Gomez et al., 1963; Holden et al., 1972; Amacher and Shillito, 1973; Cunliffe, 1974; Long et al., 1974; Yasargil et al., 1976; Lang et al., 1977).

Fig. 1 Right-sided carotid arteriogram, lateral projection. Two smaller feeders can be seen $(<)$, in addition to the main feeder artery $(M F)$ arising from the posterior cerebral artery $(A C P)$. Note the large torcular (TOR).

\section{Case report}

Our patient, a girl, is now 20 months old. The birth was normal, birthweight was $3000 \mathrm{~g}$, and length $50 \mathrm{~cm}$; the head circumference was normal $(35.2 \mathrm{~cm})$. Three days after birth the patient was transferred to the Paediatric Department of the Odense University Hospital, because of a tendency 
to regurgitate feeds.

The infant was hypotonic, tachypnoeic, palegreyish in colour, and jaundiced; the neck veins were congested, and there was hepatomegaly. The first and second heart sounds were split and there was a soft early systolic murmur in the third and fourth intercostal spaces. $X$-ray film of the chest showed an enlarged heart and an electrocardiogram showed right-sided hypertrophy.

The patient was treated with digoxin and diuretics. Heart catheterisation was carried out because congenital heart disease was suspected, and showed a left-to-right shunt at atrial level (pulmonary/systemic flow ratio $2 \cdot 0$ ), severe pulmonary arterial hypertension $(105 / 47 \mathrm{mmHg})$, and a high oxygen saturation $(99 \%)$ in the jugular vein at the base of the skull. These observations indicated an arteriovenous shunt in the cerebral circulation, with resulting congestive heart failure.
Further examination revealed that there was a very loud cranial bruit, synchronous with the pulse. A brain scan showed increased uptake in the midline posteriorly, around the area of the great vein of Galen. Bilateral carotid arteriography using Seldinger's technique showed opacification of a large aneurysm of the vein of Galen (approximately $5 \times 5 \times 5 \mathrm{~cm})$. The aneurysm was fed by 3 arteries on the right side and one on the left, arising from dilated posterior cerebral arteries. There were no feeders from the anterior cerebral artery. The torcular Herophili (confluens sinuum) was extremely dilated (Fig. 1 and 2).

The condition of the child improved only slightly within the first 3 months. Therefore a right-sided basal/temporal osteoplastic craniotomy was carried out. The main feeding artery from the posterior cerebral artery, and two smaller branches entering the anterior part of the aneurysm were

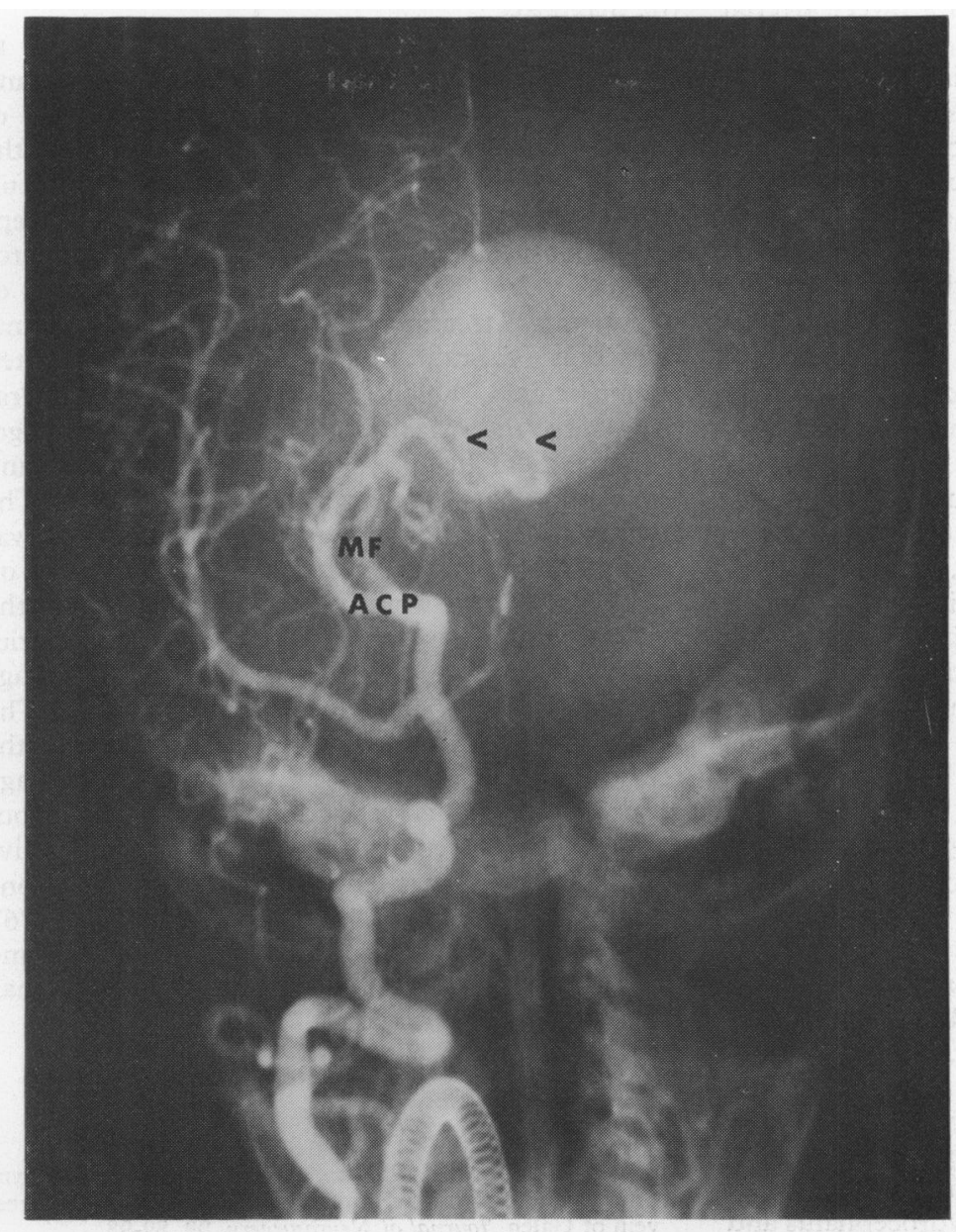

Fig. 2 AP projection, showing the main feeder $(M F)$ and the two smaller feeders $(<)$ to the aneurysm of the great vein of Galen. 
exposed and ligated, using a microsurgical technique (Raimondi, 1976). No feeding arteries were seen to arise from the posterior thalamic arteries.

The postoperative course was uncomplicated, and 3 months later a left-sided basal/temporal osteoplastic craniotomy was performed with ligation of the large left-sided feeding artery. The postoperative course was uncomplicated and drug treatment was discontinued. Follow-up examination of the child at the age of 12 months and at 20 months disclosed no signs of hydrocephalus, and the cranial bruit had disappeared. The child was 3 SD below normal weight, but this was $0.5 \mathrm{SD}$ more than her weight at the age of 3 months. Her mental condition was normal for age. A brain scan was normal and chest $x$-ray revealed a heart of normal size.

\section{Discussion}

Aneurysms of the great vein of Galen are divided into two groups: (1) solitary, with a direct arterial supply to a dilated vein of Galen, and (2) arteriovenous malformations which drain into the great vein of Galen (Litvak et al., 1960). The feeding arteries arise from the posterior cerebral, the superior cerebellar, the anterior cerebral, or most commonly from the posterior thalamic arteries. Our patient had a malformation of the first type. Symptoms are noted in early childhood. The most common clinical feature is probably hydrocephalus, resulting from direct pressure of the aneurysm on the midbrain, thus producing aqueductal stenosis. The most dangerous clinical effect, however, is the arteriovenous shunt, which overloads the heart, with resulting heart failure. The cerebral circulation in these patients may comprise 80 per cent or more of the cardiac output, with flooding of the right side of the heart with highly oxygenated blood under high pressure (Levine et al., 1962; Gomez et al., 1963; Amacher and Shillito, 1973). Bleeding from an aneurysm of the vein of Galen occurs only rarely because of the very thick walls which, microscopically, resemble the dura mater (Matson, 1969).

In 1973 Amacher and Shillito reviewed 42 cases of malformations similar to ours. Fourteen neonates developed signs of congestive cardiac failure immediately after birth. Eleven of these had severe heart failure, and 10 died before an operation could be performed; the other died immediately after operation from heart failure. Three neonates had mild heart failure during the first days of life, and responded well to drug treatment. These children survived operation during the first year of life. A further 22 patients had symptoms between 1 and 12 months of age, usually hydrocephalus and seizures. Significant cardiomegaly was noted on the chest $x$-ray films of only 7 of these children, while mild cardiac failure was clinically apparent in 2 of them. In a last group of 6 older patients, from $3 \frac{1}{2}$ to 27 years of age, the main clinical symptom was headache, and in 2 of the children there were recurring episodes of exercise syncope. Five of these patients were subjected to operation, and 2 died after operation because of inadequate haemostasis and increased intracranial pressure. Thus, onethird of all patients were neonates with heart failure.

Though intracranial arteriovenous aneurysms are a rare cause of right-sided congestive heart failure in the neonatal period, this possible diagnosis should be borne in mind in infants with unexplained right-sided heart failure. Auscultation of the cranium, with phonocardiographic recordings, can be of diagnostic importance. Heart catheterisation and cerebral angiography should confirm the diagnosis.

Our aim when treating these children is to reduce the size of the arteriovenous shunt, and operative treatment is therefore the method of choice. This involves careful clipping of all the arterial feeders. Access to these may be very difficult with conventional techniques, because of the deepseated position of the malformation. A microsurgical technique is therefore an essential part of the operative treatment; with this there is minimal retraction of brain tissue and a well-illuminated operative field, which ensures a much safer operative course than was possible only a few years ago.

Our patient had no signs of hydrocephalus and the cerebral condition was apparently good. The angiographic studies showed that the aneurysm was fed by branches of the posterior cerebral arteries on both sides. There were no arterial feeders from the anterior cerebellar or posterior thalamic arteries and we, therefore, decided to use the two-stage procedure as described by Raimondi (1976). The advantages of this method are easy access to the feeding arteries and, by the use of the two-stage procedure, a gradual reduction in the arteriovenous shunt, thus lessening the risk of postoperative complications (Amacher and Shillito, 1973; Long et al., 1974; Raimondi, 1976; Yasargil et al., 1976). The postoperative course was quite uneventful and the child is developing normally after more than 20 months of observation.

\section{References}

Amacher, A. L., and Shillito, J, jun (1973). The syndromes and surgical treatment of aneurysms of the great vein of Galen. Fournal of Neurosurgery, 39, 89-98. 
Cunliffe, P. N. (1974). Cerebral arteriovenous aneurysm presenting with heart failure. British Heart fournal, 36, 919-923.

Gomez, M. R., Whitten, C. F., Nolke, A. Bernstein, J., and Meyer, J. S. (1963). Aneurysmal malformation of the great vein of Galen causing heart failure in early infancy. Pediatrics, 31, 400-411.

Holden, A. M., Fyler, D. C., Shillito, J., jun, and Nadas, A. S. (1972). Congestive heart failure from intracranial arteriovenous fistula in infancy. Pediatrics, 49, 30-39.

Lang, D., Hofstetter, R., Weisser, M., and von Bernuth, G. (1977). Die kongenitale zerebrale arterio-venöse Fistel mit Herzin-suffizienz im Neugeborenenalter. Monatsschrift für Kinderheilkunde, 125, 39-43.

Levine, O. R., Jameson, A. G., Nellhaus, G., and Gold, A. P. (1962). Cardiac complications of cerebral arteriovenous fistula in infancy. Pediatrics, 30, 563-575.

Litvak, J., Yahr, M. D., and Ransohoff, J. (1960). Aneurysms of the great vein of Galen and midline cerebral arteriovenous anomalies. Fournal of Neurosurgery, 17, 945-954.
Long, D. M., Seljeskog, E. L., Chou, S. N., and French, L. A. (1974). Giant arteriovenous malformations of infancy and childhood. Fournal of Neurosurgery, 40, 304-312.

Matson, D. D. (1969). Neurosurgery of Infancy and Childhood, pp. 766-772. Charles C. Thomas, Springfield, Illinois.

Raimondi, A. (1976). Surgical management of arteriovenous malformation of the galenic system - variations in approach and microsurgical technique (abstract). In International Society for Paediatric Neurosurgery. Fourth Scientific Meeting, Würzburg.

Yasargil, M. G., Antic, J., Laciga, R., Jain, K. K., and Boone, S. C. (1976). Arteriovenous malformations of vein of Galen: microsurgical treatment. Surgical Neurology, 6, $195-200$.

Requests for reprints to Dr Kaj Lillquist, Paediatric Department $H$, Odense Hospital, 5000 Odense, Denmark. 